International Journal of Medical Sciences

ISSN 1449-1907 www.medsci.org 2006 3(2):79-83

Review

(C)2006 Ivyspring International Publisher. All rights reserved

\title{
Management of HCV Infection and Liver Transplantation
}

\author{
Thomas D. Schiano, and Paul Martin
}

Adult Liver Transplantation, Recanati/Miller Transplantation Institute, Division of Liver Diseases, Department of Medicine, The Mount Sinai School of Medicine, New York, NY, USA

Corresponding address: Thomas D. Schiano, M.D., The Division of Liver Diseases, Recanati-Miller Transplantation Institute, Box 1104, The Mount Sinai Medical Center, One Gustave Levy Place, New York, New York 10029. Phone: (212) 241-1424, (212) 2411598. Fax: (212) 241-2138. Email: thomas.schiano@mountsinai.org, paul.martin@mountsinai.org

Received: 2005.12.30; Accepted: 2006.03.01; Published: 2006.04.01

A major challenge facing liver transplant recipients and their physicians is recurrence of hepatitis $C$ virus infection following otherwise technically successful liver transplantation. Recurrent infection leads to diminished graft and patient survival. Although a number or predictors of severe recurrence have been identified, no definitive strategy has been developed to prevent recurrence. Generally the tempo of hepatitis $\mathrm{C}$ recurrence is gauged by serial liver biopsies with the decision to intervene with antiviral therapy based on local philosophy and expertise. Treating hepatitis $\mathrm{C}$ in this population has a number of major challenges including diminished patient tolerance for side-effects as well as managing the patient's immunesuppression. However sustained viral responses are possible with the potential to reduce the impact of recurrent hepatitis on the graft. However recurrent hepatitis $C$ virus infection will remain the most frequent form of recurrent disease in liver transplant programs for the foreseeable future.

Key words: recurrent hepatitis C, liver transplantation, antiviral therapy

\section{Treatment of $\mathrm{HCV}$ in the Liver Transplant Population}

Currently there are approximately 17,000 patients on liver transplant waiting lists throughout the U.S. with approximately 5,000 liver transplants performed annually $[1,2]$. Because of a critical shortage of donor livers, $10 \%$ $12 \%$ of potential recipients die before they are transplanted. About $40 \%$ of liver transplants are performed in patients having $\mathrm{HCV}$ and this number is expected to significantly rise during the next decade, especially with burgeoning rates of hepatocellular carcinoma [2,3]. Traditionally, cirrhotic patients were not considered as candidates for interferon therapy as it was believed that in the setting of hepatic encephalopathy, ascites and protein malnutrition they would not tolerate therapy and also that their liver disease would potentially decompensate with treatment. However, improved response rates using the combination of pegylated interferon and ribavirin, greater experience in using hematopoietic growth factor and the need to proactively treat patients on the liver transplant waiting list have all stimulated interest in treating $\mathrm{HCV}$ patients with cirrhosis $[1,4,5]$. For the foreseeable future most HCV infected transplant candidates will be viremic at the time of transplant and will therefore remain at risk for recurrent infection. The therapy of HCV post-OLT has evolved to the point where most centers base treatment decisions on the tempo of HCV recurrence on serial liver biopsies although more and larger scale studies are needed in this population.

\section{Hepatitis C Post-Liver Transplantation}

In liver transplant (LT) recipients, persistence of hepatitis $\mathrm{C}(\mathrm{HCV})$ infection in viremic recipients almost always leads to graft reinfection. In fact, serum viral titers may reach pre-transplant levels within the first few days post-operatively. Serum levels of HCV RNA peak 1-3 months post-transplant, reaching titers many fold higher than pre-transplant levels [4,6]. Furthermore, histological evidence of $\mathrm{HCV}$ recurrence occurs in over $90 \%$ of patients within 5 years of the transplant and has a variable clinical course $[1,6]$. Histological progression of HCV is accelerated after LT and can result in the fairly rapid development of graft failure and cirrhosis $[7,8,9]$. Several studies have shown that as many as $20 \%$ of HCV patients undergoing liver transplant may develop cirrhosis within 5 years, with almost $50 \%$ developing cirrhosis within a decade. Once patients develop cirrhosis from recurrent $\mathrm{HCV}$, they are at risk for the same complications as other patients including variceal bleeding, ascites and hepatocellular carcinoma. Berenguer and colleagues observed rapid hepatic decompensation in LT recipients with graft cirrhosis due to recurrent HCV $[1,4,10]$.

Recent studies looking at large numbers of patients with adequate long-term follow-up have confirmed that patients with $\mathrm{HCV}$ undergoing liver transplantation have increased morbidity and mortality and have lower 5 and 10 year survival rates when compared to patients undergoing liver transplantation for other etiologies of cirrhosis $[1,8,9]$. HCV is the most frequent indication for LT in the United States and in Europe. By the year 2020 the proportion of untreated HCV patients developing cirrhosis is expected to increase by $30 \%$, the number of cirrhotic patients with HCV to increase by $100 \%$, and the number of $\mathrm{HCV}$ cirrhotic patients developing hepatocellular carcinoma by $80 \%$ [2]. With the anticipated increase in patients requiring LT for HCV related liver disease, development of effective strategies to reduce graft failure due to $\mathrm{HCV}$ recurrence is essential.

A number of reports have described accelerated fibrosis progression post-liver transplantation and this may in part be due to the age of the donor liver allograft [10]. The median rate of fibrosis progression is between 0.3 and 0.6 stage per year post-transplant compared to 0.1 to 0.2 stage per year in immunocompetent $\mathrm{HCV}$ patients. Various risk factors for poor outcomes post-LT for $\mathrm{HCV}$ 
have been described. Berenguer et al have shown that the use of liver allografts from deceased donors older than age 60 is associated with a more severe recurrence of $\mathrm{HCV}$ as well as a more rapid progression to cirrhosis when compared to LT recipients receiving allografts from younger donors [10]. Once patients develop cirrhosis post-transplant, the 1 and 3 year actuarial risks of decompensation are $42 \%$ and $62 \%$, respectively, vs. less than $5 \%$ by 1 year and less than $20 \%$ by 5 years in immunocompetent patients with chronic HCV infection $[1,4,5]$. A subset of patients develop a severe cholestatic form of $\mathrm{HCV}$ that rapidly progresses to graft failure, similar to the fibrosing cholestatic hepatitis that originally described in patients with recurrent hepatitis B posttransplant. Characteristically, there is a very high $\mathrm{HCV}$ serum RNA level, profound hyperbilirubinemia and high levels of alkaline phosphatase and gamma-glutamyl transferase, and liver biopsy reveals feathery degeneration predominantly in the perivenular area (Figure 1), portal tracts showing chronic inflammation ranging from mildsevere with occasional lymphoid aggregates (Figure 2) $[4,11]$. Actively proliferating bile ductiles are often seen. Risk factors for severe recurrent $\mathrm{HCV}$ include advanced donor age, HCV genotype 1, high HCV RNA levels before and after transplant, early histological recurrence of $\mathrm{HCV}$, concomitant cytomegaloviral infection, the use of $\mathrm{T}$ lymphocyte-depleting immunosuppressive agents such as OKT3, and treatment of presumed acute cellular rejection with pulse corticosteroids. Data are conflicting as to whether recipient age, warm or cold ischemia times, gender, HLA mismatch, ethnicity or pre-transplant severity of illness influence the rate of recurrent HCV and its severity $[1,4,5,12,13,14]$.

Figure 1. Liver needle biopsy showing severe recurrent hepatitis $\mathrm{C}$, cholestatic type. This photomicrograph shows centrilobular cholestasis causing feathery degeneration of hepatocytes (long arrow). In addition, there are foci of parenchymal necrosis including acidophilic bodies (short arrows). H\&E stain, original magnification 200x.

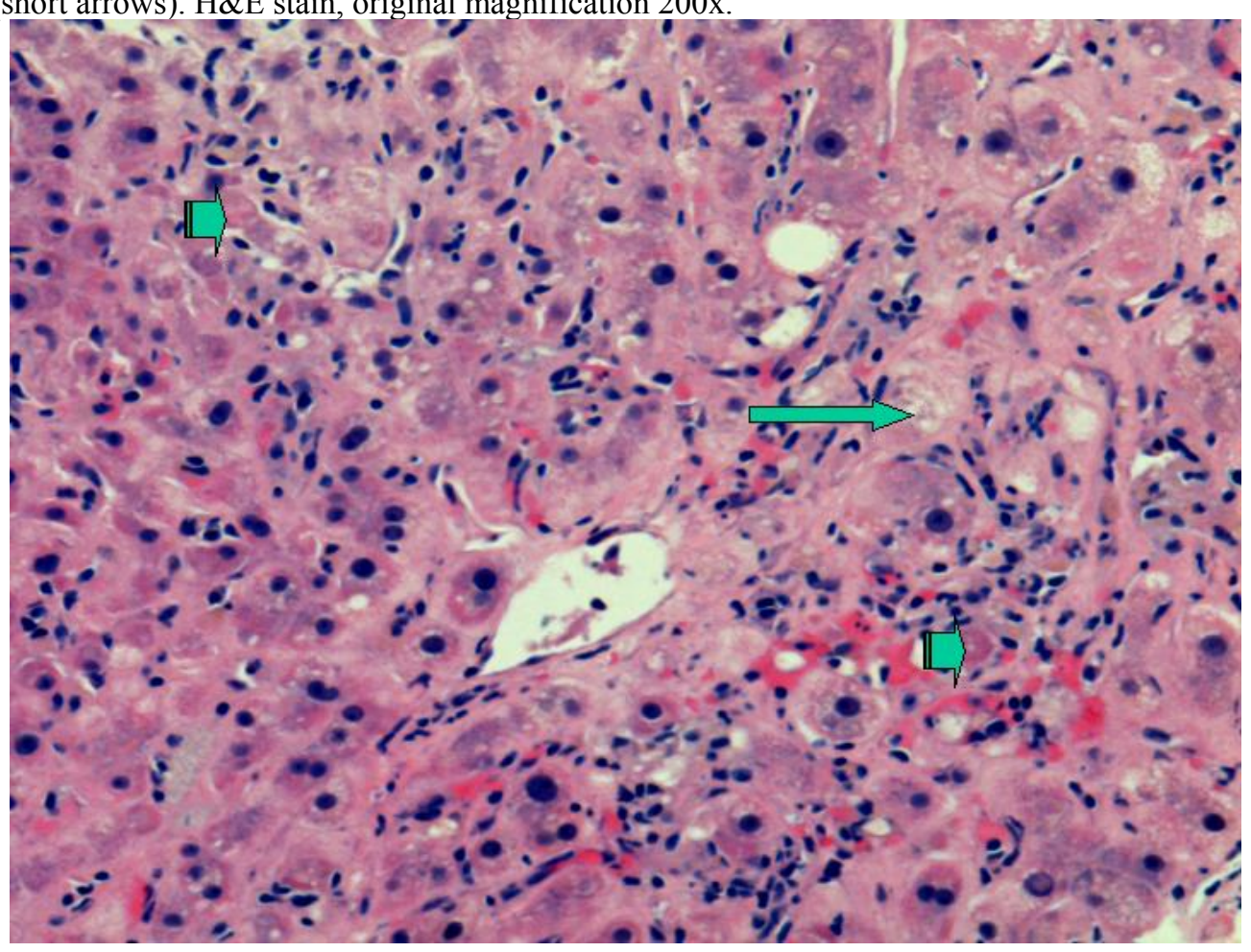

Excessive immunosuppression appears to have a deleterious effect on HCV recurrence post-liver transplant [1,15]. High dose maintenance corticosteroid therapy for the prevention of acute cellular rejection has been associated with decreased patient and graft survival in HCV-infected transplant recipients. With regard the use of cyclosporine- or tacrolimus-based immunosuppression, no significant differences in survival or in frequency/severity of $\mathrm{HCV}$ recurrence have been found. The impact, if any, of azathioprine, mycophenolate mofetil and sirolimus on HCV natural history post-liver transplant remain unclear [1,5]. It can be extremely difficult at times to differentiate between acute cellular rejection and recurrent HCV histologically even for experienced liver pathologists because most patients will have some baseline features of hepatitis on the biopsy, as well as varying degrees of the histological features that define allograft rejection such as interface inflammatory changes and bile duct damage $[4,16]$. Thus, repeated liver biopsies may be required when there is an elevation in liver chemistry tests to more reliably diagnose HCV recurrence. The optimal strategy in managing immunosuppression post-liver transplant in the HCV patient thus appears to be achieving a balance between the prevention of rejection while minimizing the potential deleterious effects of immunosuppression on recurrent HCV [1,4]. However, this is extremely difficult to achieve in most patients.

In the post-liver transplant setting the differential diagnosis of elevated liver chemistry tests is broad and includes acute cellular or chronic ductopenic rejection, bacterial or viral (CMV most frequently) infection, drug hepatotoxicity, ischemia or viral hepatitis. Approximately $20-30 \%$ of patients with recurrent HCV may have normal aminotransferases; it is for this reason that some centers favor protocol liver biopsies in $\mathrm{HCV}$ patients post-liver transplantation. Histologically, acute HCV recurrence is characterized by lobular infiltrates with varying degrees of hepatocyte necrosis 
which may evolve over time to a chronic hepatitis with significant portal and lobular infiltrates and hepatocyte necrosis, as well as portal-to-portal bridging fibrosis.

Early in the era of adult-to-adult live donor liver transplantation, preliminary reports suggested that patients undergoing this partial liver transplant had more severe HCV recurrence [1,4]. Although a well designed study from Europe did show a higher rate of graft failure in $\mathrm{HCV}$ recipients of live donor liver transplantation as compared to $\mathrm{HCV}(+)$ recipients of deceased donor livers, several more recent studies including one utilizing protocol liver biopsies and another an analysis of the UNOS database of a large number of patients, have not shown worse graft or patient survival in patients undergoing live donor liver transplantation $[17,18]$.

Several studies have shown that patients undergoing retransplantation for recurrent HCV experience significant morbidity and mortality. Although there is decreased patient and graft survival after retransplantation in general, it appears that results are even poorer for patients when the etiology of graft failure is recurrent HCV. In a large single center experience Roayaie et al noted a median survival of 12.9 months in 42 patients undergoing retransplantation because of graft failure due to recurrent HCV; 20 of the patients died within 6 months, almost all from sepsis. The presence of renal dysfunction, thrombocytopenia and coagulopathy were negative prognostic variables for survival [19]. Whether to retransplant patients with recurrent HCV is a difficult decision because of the decreased patient and graft survival that occurs after retransplantation in an era in which there are frequent deaths on the liver transplant waiting list and a finite number of donor livers. Whether a patient with HCV recurrence was unable to tolerate interferon treatment or was a virological non-responder must be considered in the decision making process when retransplantation becomes necessary, although data on this point is needed.

Figure 2. Same case as above showing a portal area with a dense lymphoid aggregate typically seen in chronic hepatitis C. Arrows point to proliferating bile ductules (ductular reaction). The bile duct is intact albeit slightly damaged. H\&E stain, original magnification $200 \mathrm{x}$

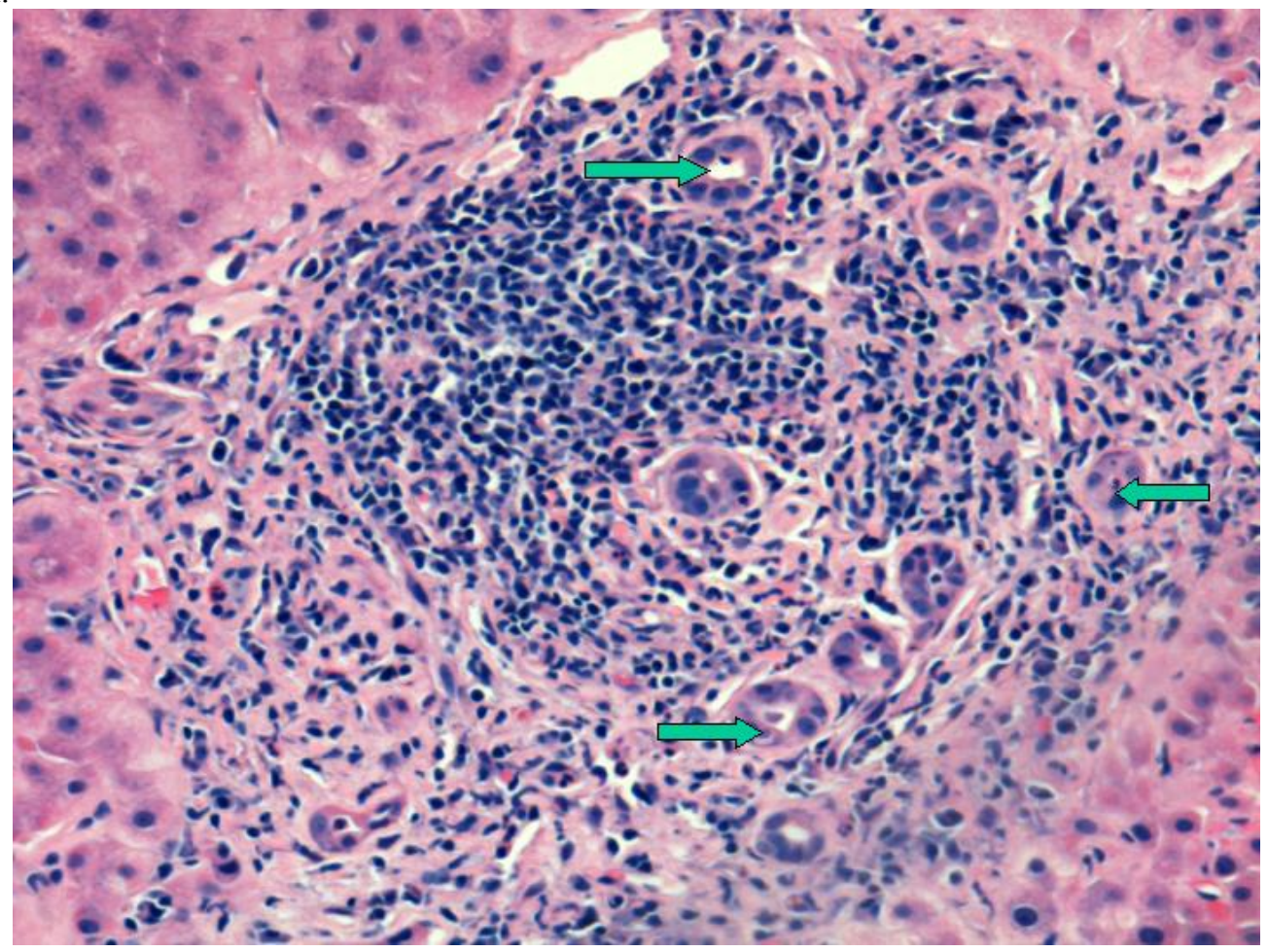

Currently, interferon-based therapies are the only effective treatment for $\mathrm{HCV}$ post-liver transplantation. Treatment early after liver transplant is difficult because of the patient's often poor performance status, their increased susceptibility to infection and rejection, and the presence of anemia and renal dysfunction that lessen the tolerability of interferon and ribavirin $[1,4,5,20,21]$. It is for these reasons, in addition to the fact that an undetectable or low viral load at the time of transplant is associated with less severe $\mathrm{HCV}$ recurrence, that pretransplant antiviral therapy is frequently attempted [22]. To date, preemptive treatment to prevent $\mathrm{HCV}$ recurrence post-liver transplantation has not been shown to be highly effective; Chalasani et al recently demonstrated less than a $10 \%$ sustained virological response rate in patients receiving 48 weeks of peginterferon alfa-2a monotherapy [23]. The First ILTS Expert Panel Consensus Conference concluded that prophylactic and preemptive antiviral interferon-based therapy should only be used in specific circumstances, such as for non-HCV patients receiving $\mathrm{HCV}(+)$ donor allografts [4]. The response rate with standard interferon monotherapy and standard interferon in combination with ribavirin to treat post-liver transplant $\mathrm{HCV}$ has generally been associated with modest response rates. However, small single center trials in patients treating established recurrent $\mathrm{HCV}$ using the combination of pegylated interferon alpha- $2 b$ and ribavirin have resulted in end-of-treatment and sustained virological response rates ranging from $27-64 \%$ and $0-36 \%$, respectively $[24,25]$. Treatment of recurrent $\mathrm{HCV}$ is limited by decreased patient tolerability necessitating frequent dose adjustment and the inability to achieve optimal dosing. Approximately $30 \%$ of patients will discontinue therapy. Often the only way of maintaining 
the blood counts is to aggressively use hematopoietic growth factors. The often poor tolerability of this population to any interferon and ribavirin regimen reflects a number of factors including concomitant immunosuppressive agents and associated renal dysfunction. An important concern has been whether interferon can induce graft rejection as has been reported in renal transplant recipients. Chalasani et al in their controlled clinical trial did not observe any increase in rejection rates in liver transplant recipients treated with pegylated alfa-2a [23]. Stravitz et al have described profound graft dysfunction following successful interferon clearance of HCV RNA with a picture suggestive of chronic ductopenic rejection [26]. One explanation may be that following clearance of $\mathrm{HCV}$ infection hepatocellular function improves and in turn leads to rejection. There have been increasing reports of pegylated interferon and ribavirin therapy possibly increasing the rates of both acute cellular and chronic ductopenic rejection [23]. Castells et al in a recent report described an SVR of $34 \%$ in genotype 1patients treated a mean of 3.4 months following OLT suggesting a role for therapy early in the course of HCV. Importantly a predictor of interferon response was an absence of treatment for acute rejection [28].

At our institution, patients with $\mathrm{HCV}$ undergo protocol liver biopsies every 6 months, and interferon and ribavirin are started only in the presence of progressive fibrosis. Firpi and colleagues from the University of Florida have described an important prognostic role for the severity of liver biopsy findings 1 year post-OLT [29]. We utilize an escalating dose regimen of both pegylated interferon and ribavirin, and we aggressively utilize hematopoietic growth factors early in treatment to help stave off the need to discontinue therapy. Although thrombocytopenia may persist after portal hypertension resolves post-transplant, it is rarely a limiting factor to pegylated interferon use. We treat patients for 12 months and check monthly laboratory testing to exclude acute and chronic rejection.

The worsening organ donor shortage has necessitated the use of $\mathrm{HCV}(+)$ allografts in recipients with HCV. It appears that short-term patient and graft survival are similar compared with a cohort of $\mathrm{HCV}(+)$ recipients receiving $\mathrm{HCV}(-)$ allografts. A $\mathrm{HCV}(+)$ patient who is HCV RNA (-) should not receive a HCV (+) allograft. As it appears that the donor allograft genotype predominates after transplantation, our center's practice is to not use $\mathrm{HCV}(+)$ donors for patients with genotype 2 and $3[4,5]$. It is prudent to avoid the use of HCV (+) livers from older donors or those having any histological damage.

\section{Conflict of Interest} exists.

The authors have declared that no conflict of interest

\section{References}

1. Brown RS. Hepatitis $\mathrm{C}$ and liver transplantation. Nature 2005;436:973-8.

2. Davis GL, Albright JE, Cook SF, Rosenberg DM. Projecting future complications of chronic hepatitis $\mathrm{C}$ in the United States. Liver Transpl 2003;9:331-8.

3. El-Serag HB. Hepatocellular carcinoma: recent trends in the United States. Gastroenterology 2004;127:S27-34.

4. Wiesner RH, Sorrell M, Villamil $\mathrm{F}$ and the International Liver Transplantation Society Expert Panel. Report of the first international liver transplantation society expert panel consensus conference on liver transplantation and hepatitis C. Liver Transpl 2003;9:S1-S9.

5. Vargas HE, Rodriguez-Luna H. Management of hepatitis $\mathrm{C}$ virus infection in the setting of liver transplantation. Liver Transpl 2005; 11:479-89.

6. Charlton M. Liver biopsy, viral kinetics, and the impact of viremia on severity of hepatitis C virus recurrence. Liver Transpl 2003;9:S58S62.

7. Chopra KB, Demetris AJ, Blakolmer K, Dvorchik I, Laskus T, Wang LF, Araya VR, Dodson F, Fung JJ, Rakela J, Vargas HE. Progression of liver fibrosis in patients with chronic hepatitis $\mathrm{C}$ after orthotopic liver transplantation. Transplantation 2003;76:1487-1491.

8. Gane EJ, Portmann BC, Naoumov NV, Smith HM, Underhill JA, Donaldson PT, Maertens G, Williams R. Long-term outcome of hepatitis C infection after liver transplantation. N Engl J Med 1996;334:815-820.

9. Forman LM, Lewis JD, Berlin JA, Feldman HI, Lucey MR. The association between hepatitis $\mathrm{C}$ infection and survival after orthotopic liver transplantation. Gastroenterology 2002;122:889-96.

10. Berenguer M, Prieto M, San Juan F, Rayon JM, Martinez F, Carrasco D, Moya A, Orbis F, Mir J, Berenguer J. Contribution of donor age to the recent decrease in patient survival among HCV-infected liver transplant recipients. Hepatology 2002;36:202-210.

11. Doughty AL, Spencer JD, Cossart YE, McCaughan GW. Cholestatic hepatitis after liver transplantation is associated with persistently high serum hepatitis C virus RNA levels. Liver Transpl Surg 1998;4:15-21.

12. Burak KW, Kremers WK, Batts KP, Wiesner RH, Rosen CB, Razonable RR, Paya CV, Charlton MR. Impact of cytomegalovirus infection, year of transplantation, and donor age on outcomes after liver transplantation for hepatitis C. Liver Transpl 2002;8:362-369.

13. Charlton M, Seaberg E. Impact of immunosuppression and acute rejection on recurrence of hepatitis C: results of the National Institute of Diabetes and Digestive and Kidney Diseases Liver Transplantation Database. Liver Transpl Surg 1999;5:S107-S114.

14. Ghobrial RM, Steadman R, Gornbein J, Lassman C, Holt CD, Chen P, Farmer DG, Yersiz H, Danino N, Collisson E, Baquarizo A, Han SS, Saab S, Goldstein LI, Donovan JA, Esrason K, Busuttil RW. A 10-year experience of liver transplantation for hepatitis C: analysis of factors determining outcome in over 500 patients. Ann Surg 2001;234:384-393.

15. McCaughan GW, Zekry A. Impact of immunosuppression on immunopathogenesis of liver damage in hepatitis $C$ virus-infected recipients following liver transplantation. Liver Transpl 2003;9:S21S27.

16. Demetris AJ, Belle SH, Hart J, Lewin K, Ludwig J, Snover DC, Tillery GW, Detre K. Intraobserver and interobserver variation in the histopathological assessment of liver allograft rejection. The Liver Transplantation Database (LTD) Investigators. Hepatology 1991;14:751-5.

17. Baltz AC, Trotter JF. Living donor liver transplantation and hepatitis C. Clin Liver Dis 2003;7:651-665.

18. Russo MW, Galanko J, Beavers K, Fried MW, Shrestha R. Patient and graft survival in hepatitis $C$ recipients after adult living donor liver transplantation in the United States. Liver Transplant 2004;10:340-346.

19. Roayaie S, Schiano TD, Thung SN, Emre SH, Fishbein TM, Miller $\mathrm{CM}$, Schwartz ME. Results of retransplantation for recurrent hepatitis C. Hepatology 2003;38:1428-36.

20. Crippin JS, McCashland T, Terrault N, Sheiner P, Charlton MR. A pilot study of the tolerability and efficacy of antiviral therapy in hepatitis $\mathrm{C}$ virus-infected patients awaiting liver transplantation. Liver Transpl. 2002;8:350-5.

21. Shakil AO, McGuire B, Crippin J, Teperman L, Demetris AJ, Conjeevaram H, Gish R, Kwo P, Balan V, Wright TL, Brass C, Rakela J. A pilot study of interferon alfa and ribavirin combination in liver transplant recipients with recurrent hepatitis C. Hepatology 2002;36:1253-1258.

22. Everson GT, Trotter J, Forman L, Kugelmas M, Halprin A, Fey B, Ray C. Treatment of advanced hepatitis $C$ with a low accelerating dosage regimen of antiviral therapy. Hepatology 2005;42:255-62. 
23. Chalasani N, Manzarbeitia C, Ferenci P, Vogel W, Fontana RJ, Voigt M, Riely C, Martin P, Teperman L, Jiao J, Lopez-Talavera JC; Pegasys Transplant Study Group. Peginterferon a2a for hepatitis $C$ after liver transplantation: two randomized, controlled trials. Hepatology 2005;41:289-298.

24. Rodriguez-Luna H, Khatib A, Sharma P, De Petris G, Williams JW, Ortiz J, Hansen K, Mulligan D, Moss A, Douglas DD, Balan V, Rakela J, Vargas HE. Treatment of recurrent hepatitis $C$ infection after liver transplantation with combination of pegylated interferon alpha2b and ribavirin: an open-label series. Transplantation 2004;77:190-194.

25. Neff GW, Montalbano M, O'Brien CB, Nishida S, Safdar K, Bejarano PA, Khaled AS, Ruiz P, Slapak-Green G, Lee M, Nery J, De Medina M, Tzakis A, Schiff ER. Treatment of established recurrent hepatitis $C$ in liver-transplant recipients with pegylated interferon-alfa- $2 b$ and ribavirin therapy. Transplantation 2004;78:1303-1307.

26. Stravitz RT, Shiffman ML, Sanyal AJ, Luketic VA, Sterling RK, Heuman DM, Ashworth A, Mills AS, Contos M, Cotterell AH, Maluf D, Posner MP, Fisher RA. Effects of interferon treatment on liver histology and allograft rejection in patients with recurrent hepatitis C following liver transplantation. Liver Transplant 2004;10:850-858.

27. Saab S, Kalmaz D, Gajjar NA, Hiatt J, Durazo F, Han S, Farmer DG, Ghobrial RM, Yersiz H, Goldstein LI, Lassman CR, Busuttil RW. Outcomes of acute rejection after interferon therapy in liver transplant recipients. Liver Transplant 2004;10:859-867.
28. Castells L, Vargas V, Allende H, Bilbao I, Luis Lazaro J, Margarit C, Esteban R, Guardia J. Combined treatment with pegylated interferon (alpha-2b) and ribavirin in the acute phase of hepatitis $\mathrm{C}$ virus recurrence after liver transplantation. J Hepatol 2005;43:53-9.

29. Firpi RJ, Abdelmalek MF, Soldevila-Pico C, Cabrera R, Shuster JJ, Theriaque D, Reed AI, Hemming AW, Liu C, Crawford JM, Nelson DR. One-year protocol liver biopsy can stratify fibrosis progression in liver transplant recipients with recurrent hepatitis $C$ infection. Liver Transpl 2004;10:1240-7.

\section{Author biography}

Thomas D. Schiano, M.D. is Associate Professor of Medicine, Medical Director of Liver Transplantation and Director of Clinical Hepatology at The Mount Sinai Medical Center, New York. His current research interests include the diagnosis and management of hepatitis $C$ in the peri-liver transplant period, as well as the management of the complications of chronic liver diseases.

Paul Martin M.D. is Professor of Medicine at Mount Sinai School of Medicine New York and Associate Director of the Division of Liver Diseases. He has a major interest in the management of viral hepatitis in organ transplantation and chronic kidney disease. 